\title{
Problematizando a Reforma Psiquiátrica na Atualidade: a saúde mental como campo da práxis'
}

\section{Questioning the Psychiatric Reform nowadays: mental health as a field of praxis}

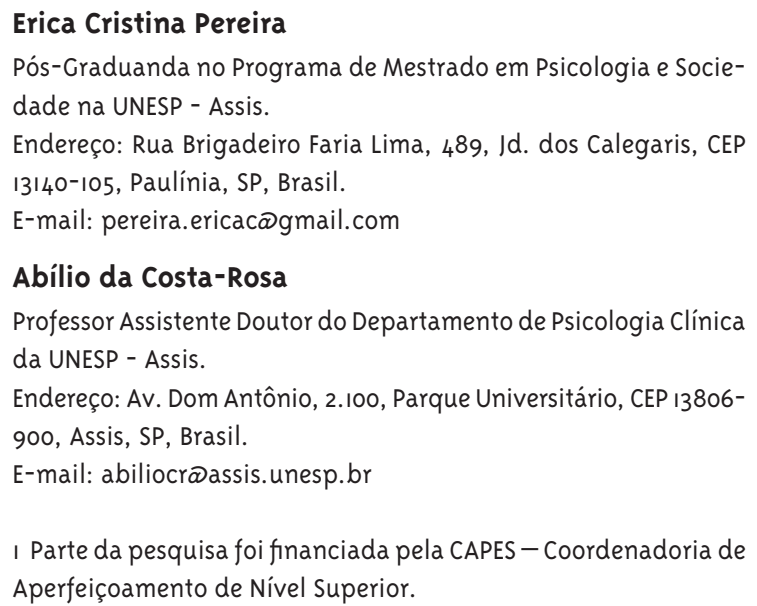

\section{Resumo}

A Saúde Mental, encarnada sob o modelo da Reforma Psiquiátrica, e o Movimento Antimanicomial não desconsideram a produção do conhecimento sobre aquele campo, sobretudo em decorrência da consolidação da Saúde Coletiva como campo do saber. $\mathrm{O}$ artigo explora alguns autores que tomam a Saúde Mental como novo campo de conhecimento, introduzindo um novo paradigma na percepção da saúde - Doença e Atenção -, contudo, o objetivo é introduzir a Atenção Psicossocial como meio para efetivar as práticas transdisciplinares e multiprofissionais. A possibilidade é que a Saúde Mental provoca desdobramentos na Saúde, consolidando as políticas públicas. Na prática, ainda há o aprisionamento ao modelo hospitalocêntrico-medicamentoso, existindo percalços a serem superados através do aproveitamento das brechas capazes de romper o instituído.

Palavras-chave: Saúde Coletiva; Saúde Mental; Atenção Psicossocial. 


\section{Abstract}

Mental Health, in the form of the Psychiatric Reform, and the Anti-Asylum Movement do not ignore the production of knowledge about that field, mainly due to the consolidation of Public Health as a field of knowledge. The article explores some authors who consider Mental Health as a new field of knowledge, introducing a new paradigm in the perception of health - Disease and Care -; however, the goal is to introduce Psychosocial Care as a means to enforce the transdisciplinary and multiprofessional practices. The possibility is that mental health produces developments in Health, consolidating the public policies. In practice, the hospital-centered and drug-based model still predominates, and there are setbacks to be overcome by taking advantage of loopholes capable of breaking with what is instituted.

Keywords: Public Health; Mental Health; Psychosocial Care.

\section{Problematizando a Reforma Psiquiátrica na Atualidade: a Saúde Mental como campo da práxis}

No desenvolvimento histórico da Saúde Pública, verificamos que as ações sempre se pautaram no campo da coletividade, momento no qual as direcionavam a favor da comunidade e do bem-estar social (Rosen, 2006). Conforme se desenvolveram as ações sanitárias, os setores financeiros ampliaram sua atuação sobre o Estado, a assistência passou a ser centrada no indivíduo e cada vez menos abrangendo a coletividade, o bem-estar social e a assistência integral.

Rosen (2006) aponta para algumas mudanças na atenção à Saúde Mental. A criação dos hospícios em consonância com o Hospital Geral teve a função de segregar. Posteriormente, ambos se destacaram pela necessidade de qualificar o tratamento.

No entanto, o tratamento moral pouco efeito teve sobre os doentes mentais, tampouco promoveu alguma mudança social a respeito da discriminação e o uso desses espaços como depósitos proliferadores da exclusão e disseminadores das ações avessas a um tratamento eficaz. Nesses lugares, muitas vezes, os doentes mentais eram usados como "cobaias" pela medicina, que considerava a loucura como um efeito orgânico.

O campo da Saúde Coletiva, influenciado pelo saber médico, é definido pelo paradigma da ciência que se constitui por um conjunto de saberes e práticas desarticuladas, porém, que se compõem para a produção da Saúde (Pain e Almeida Filho, 1998; Carvalho, 2005). Esse campo provém tradicionalmente da Saúde Pública instituída no País, desde os anos 1950. A mudança de objetivo da saúde, até aquele período, que era a produção de saúde baseada na epidemiologia e no sanitarismo, considerava as ações diretas ao foco problemático com o objetivo de eliminar a doença.

Em meio às mudanças sociopolíticas, dos paradigmas científicos e econômicos, a Saúde foi diretamente influenciada por esses fatores, perturbando a concepção de Saúde-Doença-Atenção e passando a abranger outros aspectos para além das ações de Atenção, como o planejamento, a prevenção, a promoção de saúde e a reabilitação (Nunes, 2006). 
De acordo com Nunes (2006), a Saúde Coletiva surgiu do projeto preventivista nos anos 1950, formalizando-se nos anos 1970 e se estendendo aos cursos de formação, de sorte a estruturar recursos humanos para manejar as técnicas. A medicina social possibilitou ultrapassar a compreensão orgânica e biológica da saúde para "modelos alternativos" (Costa-Rosa, 200o), que superassem a divisão social do trabalho, a concepção de doença e cura, a desinstitucionalização, tendo em vista algumas premissas estabelecidas pelo SUS: a integralidade, o território, a humanização da gestão e dos processos de trabalho (Brasil, 1990a; 2003).

Conforme Mondoni e Costa-Rosa:

Efeitos concretos fundamentais da Reforma Sanitária na política nacional de saúde, principalmente a implantação do SUS, produziram uma série de transformações importantes que foram automaticamente transpostas para o campo da Saúde Mental, introduzindo, assim, uma nova dimensão no processo da Reforma Psiquiátrica (2010, p. 40).

Neste artigo, problematizar a consolidação da Saúde Coletiva enquanto campo disciplinar e de conhecimentos abrangentes corresponde a caracterizar a Saúde Mental, que pode ser entendida como um desdobramento da Saúde Coletiva. O artigo é relevante, pois problematiza a Reforma Psiquiátrica em seu momento atual, incluindo a análise crítica e apreciação dos "autores oficiais".

\section{A Saúde Coletiva como afirmação de um campo de conhecimento}

A definição de Saúde Coletiva é complexa, pois possui variações epistemológicas e interdisciplinares, não existindo uma teoria que as unifique.

Para Pain e Almeida Filho (1998), a Saúde Coletiva é um novo campo paradigmático. Para ambos, este se expressa como campo de conhecimento interdisciplinar, abrangendo a investigação sanitária, as intervenções em grupos ou classes sobre as questões sanitárias, epidemiológicas, planejamento/administração e as Ciências Sociais. É, ainda, multiprofissional, interinstitucional e transetorial: na prática, as ações são adequadas às necessidades do campo social, incluindo a cultura, a economia, a ideologia e outros fatores.
O avanço paradigmático que se propõe sobre a Saúde Coletiva corresponde às novas práticas transdisciplinares; além disso, esse campo é científico, porque produz saberes e conhecimentos sobre o objeto Saúde e Atenção, concebido como cuidado (Campos, 200oa). Enquanto campo científico, contribui para a definição do processo saúde/doença, investigando-o como processo social que influencia os sistemas de trabalho na articulação com as práticas sociais, a gestão e o próprio trabalho em saúde. Campos (200ob) enfatiza que a área da Saúde Coletiva ainda não se consolidou como uma nova área científica, embora imprima práticas inovadoras na atenção à saúde e influencie as políticas públicas, a gestão das Instituições de Saúde e a práxis.

Divergindo de Pain e Almeida Filho, Campos (200oa) avalia que a Saúde Coletiva é um campo científico o qual supera o da Saúde Pública, contribuindo para a formação do Sistema Único de Saúde - SUS e para a compreensão do processo saúde-doença. A construção teórica sobre esse campo possivelmente sugere a conjunção entre as práticas e a teoria, apesar de as ações serem interdisciplinares e multiprofissionais.

Ao problematizar o campo de conhecimento na sua ação compreendida como práxis - junção de uma nova concepção de saúde-doença e de ações -, estabelecemos um avanço conceitual que corresponde às mudanças paradigmáticas que se materializam em suas práticas.

\section{A crise da Saúde}

Novamente se referindo ao campo da Saúde Coletiva, Pain e Almeida Filho (1998) apontam para a crise da Saúde Pública, mais especificamente no complexo promoção-saúde-doença-cuidado, precisando de maior alteração paradigmática relacionada às questões da vida, saúde e sofrimento.

A crise da Saúde pode ser entendida de modo amplo: historicamente, os indivíduos latino-americanos tendem a depreciar os serviços públicos e a valorizar os serviços privados (complementares) de saúde. Em nossa sociedade, até então, operam os indicadores de saúde associados ao nível econômico (Rosen, 2006; Brasil, 199ob), como, por exemplo, a realização de check-up, ou seja, a questão que coloca em crise a Saúde Pública é: quanto você paga por 
uma consulta médica ou exames especializados?

A crise é também decorrente da diferença da gestão das políticas públicas, gestão administrativa da Instituição e gestão das ações clínicas desenvolvidas no equipamento de Saúde. Em muitos casos, a conciliação entre as políticas públicas e a gestão da Atenção ofertada emperra no antagonismo dos interesses entre a demanda do sujeito, do trabalhador da saúde, do coordenador do equipamento de saúde e do gestor público.

\section{A Saúde e os conflitos no Estado}

Na Saúde Coletiva, o modo de vida influencia na consolidação das políticas públicas. Algumas ações de Saúde revelam o conflito entre o Estado e a sociedade, o coletivo e o individual, o público e o privado (Rosen, 2006). As relações entre a política, a economia e a organização da sociedade refletem no campo da Saúde e no modo como se faz o cuidado. Há eclosão das contradições sociais associadas aos interesses e valores, os quais, apoiados nas características do Modo Capitalista de Produção, têm resultado na disseminação das doenças, sobretudo no sofrimento psíquico.

A política brasileira de Saúde Mental é pertinente, se considerarmos a distinção de Eduardo Passos, ${ }^{2}$ a partir da Reforma Sanitária. A existência das políticas de Estado, governo e políticas públicas culminou na criação e consolidação do SUS.

De acordo com Passos, a política de Estado consiste nas ações e planejamento das políticas para todos os cidadãos, atendendo aos princípios comuns para qualquer cidadão brasileiro, de forma que as políticas operam no âmbito nacional, independendo da ideologia e da política partidária. A política de governo está associada às suas mudanças, ou seja, prefeitos, governadores e presidente, no sentido de que as alterações dos gestores, a cada quatro anos, acarretam no cumprimento dos interesses políticopartidários e ideológicos.

A Política Pública opera no campo do bem-estar social e do bem comum, é influenciada pela Política de Estado e submetida à Política de Governo. Tende a refletir nas ações setoriais, como no campo da Saúde, Assistência Social, Criança e Idoso, Mulheres, Indígenas etc., podendo ser sancionada na forma de Resoluções, Decretos-Leis e Portarias; portanto, há pouca mobilidade dessas políticas.

As Políticas de Governo mudam constantemente, devido aos interesses individuais e financiadores das campanhas político-partidárias; por fim, as políticas públicas perduram por mais tempo, dependendo de votação nas Assembleias Legislativas. Os movimentos ideológicos têm o caráter de transição paradigmática que atrelam o surgimento de um novo conceito, todavia, as Políticas Públicas mantêm uma causa e conservam as ideias principais, havendo poucas alterações e modificações, além de trazerem em seu cerne dois conceitos - a Reforma Política e a Reforma Seccional (Dahl, 2001). O primeiro conceito corresponde à inclusão de todas as Políticas Públicas que são rodeadas pela política de Estado e de governo; já o segundo concerne a um setor determinado, específico - saúde, educação, assistência social e outros (Dahl, 2001).

A pertinência da consolidação das Políticas Públicas e demais Políticas - as de Estado e a de Governo - reforçam os aspectos ético-políticos e sociais que favorecem a Reforma Psiquiátrica. A modificação das Políticas Públicas pode interferir na transição paradigmática, fazendo-a avançar ou reforçando os preceitos do Paradigma Psiquiátrico (medicalizador e hospitalocêntrico).

\section{O ensejo para a Reforma Psiquiátrica no Brasil}

A discussão sobre o campo da Saúde Coletiva e as Políticas Públicas contribui para problematizar a Reforma Psiquiátrica no Brasil.

A Gestão e a Atenção dos equipamentos de Saúde modificaram-se a partir dos processos históricos que comporão o movimento ideológico da Reforma Sanitária, resultando na construção do SUS. Concomitantemente se desdobraram na Reforma Psiquiátrica. A primeira caracterizou-se por ações

\footnotetext{
2 Eduardo Passos é professor da Universidade Federal Fluminense UFF-RJ e foi consultor do Ministério da Saúde para a implantação da Política Nacional de Humanização do SUS (2003-2008). Participou de mesa de discussão sobre o Programa de Humanização do SUS, em evento realizado em junho de 2008, em Marília-SP, referente ao polo de Educação Permanente no Colegiado de Gestão Regional (CGR) da

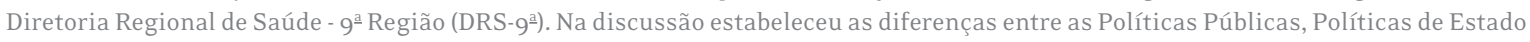
e Políticas de Governo.
} 
verticalizadas, centralização do governo federal, setor privado na área da assistência médico-hospitalar, setorialização, culminando na separação da Saúde Pública e assistência médica previdenciária (Lima e col., 2005).

A base do Movimento Sanitário surgiu com os Departamentos de Medicina Preventiva que conciliavam o conhecimento e a prática política, ampliando o campo da ação e envolvendo a sociedade civil nas suas demandas. A medicina comunitária (Carvalho, 2005) influenciou o Movimento, com propostas de desmedicalização, autocuidado, foco na Atenção Primária realizada por não profissionais, revitalização da medicina tradicional, emprego de tecnologia apropriada e formação mais integral do profissional. Nesse sentido, o Movimento confrontava o modelo preventivo-liberal preventivismo que visava reformular o objeto da saúde e superar a visão biologista e orgânica.

A promulgação das Leis nos 8.08 o e 8.142 (Brasil, 1990a:199ob) institucionalizou o SUS como uma política pública. Nesse período, já existia o projeto de lei que originou a atual lei federal referente à Reforma Psiquiátrica. Esta ficou "materializada" na Lei nํㅜ 10.216 ou da Reforma Psiquiátrica, que propunha redirecionar o modelo assistencial em Saúde Mental, dispondo sobre a proteção e os direitos das pessoas portadoras de transtornos mentais (Brasil, 2001).

No entanto, a Reforma Psiquiátrica não sugeriu um modelo de Atenção à Saúde Mental, apenas ressaltou a necessidade da desinstitucionalização dos sujeitos em longas internações psiquiátricas, porém, após a consolidação da Reforma, surgiu a Política Nacional de Saúde Mental, em 2003. Os pressupostos da Reforma Psiquiátrica marcaram algumas características paradigmáticas importantes. De modo geral, a Reforma Sanitária e principalmente a Reforma Psiquiátrica trouxeram importantes melhorias para o novo modelo de Atenção em Saúde Pública, atingindo as Instituições e suas práticas e inscrevendo novas formas de promover saúde e produzi-la (Amarante, 2007; Merhy e Amaral, 2007; Costa-Rosa, 2000; Costa-Rosa e col., 2003).

Além disso, ocorreram mudanças ideológicas no campo social, incluindo trabalho de saúde focado no território (Rotelli e col., 1990), cujo destaque passou a ser a Atenção Primária, com o distanciamento da prática por meio de um discurso que organizava as práticas institucionais.

A transição paradigmática pode ser fomentada nas relações intrainstitucionais ou interinstitucionais. Do ponto de vista, intrainstitucional, Devera (2005) aponta que a horizontalidade nas relações de poder, a participação do sujeito do sofrimento no tratamento e ainda dos trabalhadores nas relações decisórias contribuem para a modificação das relações de trabalho e da Atenção; deve haver a integração dos trabalhadores visando superar a fragmentação imposta pelo Modo Capitalista de Produção.

\section{As experiências que influenciaram a Reforma Psiquiátrica no Brasil}

A Reforma Psiquiátrica marcou o processo de desinstitucionalização, o qual é diverso da desospitalização. Esta representou a saída da instituição hospitalar sem obrigatoriamente desinstitucionalizar a Atenção ofertada ao sujeito, submetido à lógica de funcionamento hospitalar. No entanto, a primeira representou a ideia de abolir a instituição, local onde se manifestam as pulsações, ou seja, não existe prática humana sem o processo de instituir: dessa forma, verificamos que a instituição é autoprodutora de seu processo de instituir (Baremblit, 1994; Lapassade, 1983). A instituição oculta um paradigma, logo, a desinstitucionalização concretiza-se em relação ao paradigma médico-hospitalocêntrico-medicamentoso (Costa-Rosa, 200o), apenas a forma mais recorrente de se operar na Saúde Mental.

O Movimento Antimanicomial fundamentou-se nas experiências de desinstitucionalização italiana e francesa, cujos primórdios deram-se em Trieste e Gorizia, por meio da ideologia difundida por Franco Basaglia (Desviat, 1999; Amarante, 2007). As correntes difundidas influenciaram na experiência brasileira.

As Comunidades Terapêuticas (na Inglaterra e EUA) propunham reformas na instituição psiquiátrica através de medidas fundamentadas na administração, com o objetivo de provocar mudanças na dinâmica institucional, pela democratização e o aumento da participação dos asilados em reuniões diárias, as quais seriam o analisador da democracia na relação equipe-paciente (sujeito em sofrimento) 
(Amarante, 1995; 2007).

A Psicoterapia Institucional (na França) foi uma experiência surgida no Hospital Saint-Alban, fundamentada nas ideias de François Tosquelles, que acreditava na reflexão e questionamento da instituição psiquiátrica, tendendo a horizontalizar as relações intrainstitucionais bem como questionar o poder médico (idem).

Ambas as correntes tratam da criação de um discurso socialmente aceito e fundamentado no contexto grupal, todavia, pouco efeito tiveram sobre a Atenção à loucura, pois significaram mudanças restritas à instituição, por outro lado, representando a oportunidade de problematizar os "sintomas institucionais".

A Psiquiatria de Setor (também na França) atende ao princípio da intersetorialidade do SUS, e a experiência é bastante semelhante à Estratégia de Saúde da Família (ESF). Na prática, realiza-se o tratamento do sujeito no seu meio social, sendo que o tratamento hospitalar fica restrito à urgência/ emergência. O território é dividido por setores geográficos, nos quais há equipes multiprofissionais com a finalidade de realizar o tratamento de modo integral, com enfoque na prevenção (idem).

A Psiquiatria Preventiva ou Comunitária (nos Estados Unidos) é o desdobramento da experiência supracitada. Contudo, o território para a Psiquiatria passou a ser um objeto definido; intensificou-se a lógica da doença e cura concomitantes à prevenção e erradicação dos males da sociedade, permanecendo um padrão de normalidade (idem). Nessa ideia de prevenção, prevaleceu o paradigma médico em congruência com as ações do país estadunidense, "um dos berços" do Modo Capitalista de Produção. Consequentemente, a Saúde sofreu os efeitos da divisão social do trabalho, em que a instituição produz o excedente e o individualismo relega a coletividade às margens da sociedade (Birman, 2007; Costa-Rosa, 2006).
Por fim, a Antipsiquiatria efetuou crítica acirrada às ações dos psiquiatras; esse movimento foi base para a Reforma Psiquiátrica, associada ao movimento da contracultura, nos anos $1960^{3} \mathrm{o}$ objetivo era a recuperação dos doentes, a ampliação da liberdade, a capacidade de autogestão e a introdução da "Medicina Alternativa" (Amarante, 1995; 2007). Todos os conceitos passaram a ser dialetizados, inclusive o da loucura e do poder emanado das corporações médicas sobre o considerado anormal, que introduzia o controle sobre "o tempo da vida" do indivíduo, tal como a nosografia das doenças que passaram a permear as relações sociais (Foucault, 2003; 2008).

Illich (1975) desenvolveu suas críticas sobre o poder exercido pelas instituições, que ordenavam o poder (e o saber) sobre a vida das pessoas. Para ele, aquelas determinavam uma intencionalidade, influenciando as relações sociais e a relação do sujeito apoiada em uma técnica (procedimento médico) e conhecimento.

Introduziram-se igualmente algumas concepções teóricas da fenomenologia, marxismo, existencialismo e Psicanálise (Amarante, 1995; 2007). Os efeitos das mobilizações e contestações sociais provocados pelo movimento contracultural tiveram grande importância na difusão e introdução de um novo paradigma na Saúde Mental.

\section{Da Reforma Sanitária à Reforma Psiquiátrica}

As experiências relacionadas à Reforma Psiquiátrica, em outros países, produziram ressonâncias no Brasil, fortalecendo as críticas sobre a Psiquiatria instituída. As bases da Psiquiatria normativa e utilizada como um dispositivo de controle explicitavam a necessidade de uma transformação para além do aparato arquitetônico e mobiliário, ou seja, era iminente e necessária a modificação paradigmática.

Amarante (1995) definiu a Reforma Psiquiátrica em quatro parâmetros: teórico-conceitual, técnico-

\footnotetext{
30 movimento da contracultura representou uma ruptura com a estrutura biomédica, por meio de desestruturação/estruturação da dimensão cognitiva em detrimento do sistema capitalista com caráter explícito de reconstrução social, na perspectiva de se criticar o sistema estruturado na ideologia capitalista. O objetivo do movimento era implantar algo revolucionário, que simbolizasse a ruptura epistemológica e social, justificando-se por conhecimento provindo do empirismo, existência de falhas teóricas que não sustentavam a prática e o desenvolvimento das teorias, transição epistemológica do tradicional para o alternativo. Esse período foi propício para a nova construção epistemológica, com contribuição das Escolas Francesa e Inglesa. Para maiores detalhes, ver: BARROS, N.F. A construção da medicina integrativa - um desafio para o campo da saúde. São Paulo: Aderaldo \& Rothschild, 2008.
} 
assistencial, político-jurídico e sociocultural. Entendemos que esses parâmetros são fundamentais para a superação do Paradigma Psiquiátrico, todavia mostram-se insuficientes para afirmar uma "revolução" paradigmática. Nessa perspectiva, a Atenção Psicossocial apoia-se nos parâmetros definidos por Amarante, mas requer a "revolução" paradigmática para ocorrer efetivamente a transformação do Paradigma (Mondoni e Costa-Rosa, 2010; Devera, 2005; Costa-Rosa, 200o).

No Brasil, a Reforma Psiquiátrica teve seu estopim com a crise da Divisão Nacional de Saúde Mental (DINASM), que era um órgão do Ministério da Saúde (MS) responsável pela formulação das políticas de saúde do subsetor Saúde Mental. O Movimento dos Trabalhadores da Saúde Mental exigia melhorias nas condições de trabalho e na Atenção ofertada, sendo que alguns médicos denunciaram as más condições em que os pacientes do Complexo Psiquiátrico Pedro II (no Rio de Janeiro) eram tratados; o I Encontro de Coordenadores da Saúde Mental foi importante para o acontecimento da I Conferência Nacional de Saúde Mental (CNSM), em 1987 (Amarante, 2007).

Segundo Costa-Rosa e colaboradores (2003), a Reforma Psiquiátrica no Brasil valorou as críticas mais radicais à Psiquiatria provindas da Antipsiquiatria, na Inglaterra, e do movimento italiano da Psiquiatria Democrática, galgando novos conceitos e objetivos na Atenção em Saúde Mental.

A criação do primeiro equipamento substitutivo, o Centro de Atenção Psicossocial (CAPS), em Itapeva (SP), e do Núcleo de Atenção Psicossocial (NAPS), em Santos (SP) inaugurou o modo estratégico de substituição aos manicômios (Costa-Rosa, 2000; Yasui, 2006).

Todavia, a lógica operante fundamentou-se no Modo Psicossocial. Costa-Rosa (200o) o define como a maneira de produção de subjetividade sintônica com a ética da singularização. Esse "novo jeito" ou "modo" de atuação permite operar a prática social, portanto, a práxis possibilita a alteração do paradigma psiquiátrico para o Paradigma Psicossocial. Contudo, Atenção Psicossocial é a designação de uma clínica específica, porque trata-se de estratégias singulares de acordo com as demandas de sofrimento. A Atenção Psicossocial conseguiu imprimir um "novo" paradigma à Saúde Mental, podendo representar um avanço político, técnico e ideológico.

De acordo com Costa-Rosa (200o), o Modo Psicossocial é um modo de produção de saúde focado no sujeito em sofrimento, que considera a dimensão sociopolítica da doença e os fatores biopsicossocioculturais, tal como sua implicação do sujeito do sofrimento diante do tratamento e sua inserção na Instituição. A ação é integral e realizada por equipe interprofissional, havendo o diálogo de diversos saberes; com respeito à organização institucional, as relações são horizontais, ocorrendo na forma de reuniões capazes de aumentar o poder de decisão coletiva e cabendo a autogestão e a interdisciplinaridade. 0 espaço de tratamento - CAPS, NAPS, Centro de Saúde, Hospital-Dia, Ambulatório de Saúde Mental, Centros de Convivência - produz efeitos sobre o sujeito inscrito num território onde possui acesso livre, em um espaço de interlocução cuja meta final é o reposicionamento subjetivo, conjuntamente com a implicação subjetiva e sociocultural como efeito de uma ética.

\section{Os efeitos da Reforma Psiquiátrica}

Atualmente, é obsoleto falar em Reforma Psiquiátrica e Movimento Antimanicomial, pois tanto o hospital psiquiátrico quanto os manicômios são estabelecimentos que foram transformados na lógica mobiliária e até arquitetônica. 0 tratamento do sofrimento psíquico prescinde, em algumas situações, de internações e de outros equipamentos responsáveis pela reabilitação sociofamiliar. Por outro lado, os estabelecimentos difundidos pelo Ministério da Saúde como principal local de tratamento das doenças mentais são os Centros de Atenção Psicossocial, que, por vezes, não superaram a lógica manicomial e psiquiátrica.

A proposta não corresponde à desinstitucionalização, tendo em vista que o estabelecimento Centro de Atenção Psicossocial (CAPS) pode apresentar a lógica do Paradigma Psicossocial ou a do Paradigma Psiquiátrico-Medicamentoso.

Por exemplo, em 2009, ocorreu a "Marcha pela Reforma Psiquiátrica Antimanicomial”, com o objetivo de repactuar as Políticas de Saúde Mental do Ministério da Saúde com propostas de ampliação do Programa de Volta Para Casa, maior protagonismo dos sujeitos em sofrimento e trabalhadores da Saúde 
Mental, ampliação dos benefícios, como a LOAS (Lei Orgânica da Assistência Social), avanço da Economia Solidária na Saúde Mental e impulsão da IV Conferência Nacional de Saúde Mental (CNSM).

Essa "Marcha" teve o propósito de resgatar os princípios já obsoletos da Reforma Psiquiátrica ou repactuar até onde se "reformou" de fato a instituição da loucura. Diante dos feitos da Reforma Psiquiátrica, não é possível atualizá-la do ponto de vista institucional, por exemplo, uma vez que o CAPS já se transformou no estabelecimento mais divulgado e adotado como estratégia para as ações relacionadas à Saúde Mental. Por outro lado, é possível atualizar os propósitos da Reforma, quando tomamos como foco a perspectiva paradigmática. Acreditamos que existe experiência exitosa e de efetiva modificação paradigmática, mas, muitas vezes, houve um "aceite" da Reforma Psiquiátrica no aspecto protocolar, não atingindo a dimensão ideológico-política.

Cotidianamente, os equipamentos substitutivos frequentemente reproduzem a lógica manicomial, criando novas instituições que operam na lógica medicamentosa e hospitalar, pois há o confronto com a supremacia do corporativismo médico, disparidade na alocação dos equipamentos de Saúde Mental nos Territórios, influência das indústrias farmacêuticas, as quais acabam "patrocinando" a classe médica; por isso, entendemos que a mudança paradigmática ainda esteja em processo, faltando maior modificação na lógica curativa e assistencialista.

\section{Considerações Finais}

Portanto, a Reforma não deve ser considerada um "aceite ideológico", nem ser vivenciada como "entusiasmo ideológico", para organizar e rearranjar o processo de trabalho e a gestão dos equipamentos de Saúde Mental.

Apesar das melhorias implantadas pela Reforma Psiquiátrica e provocadas pelo Movimento Antimanicomial, o número de CAPSs pelo País não permite afirmar a transformação paradigmática. Nesses lugares, pode haver a repetição e a reprodução de uma lógica instituída.

A instituição deve desenvolver práxis que simbolizem o avanço paradigmático, fundamentando-se em um processo de trabalho que represente o rompimento com o Modo Capitalista de Produção. Dessa forma, a Reforma Psiquiátrica não pode ser apenas um “aceite”, na medida em que é imprescindível um novo paradigma de Atenção, que objetive rupturas permanentes, em face dos processos instituídos.

\section{Referências}

\author{
AMARANTE, P. Saúde mental e atenção \\ psicossocial. Rio de Janeiro: Fiocruz. 2007.
}

AMARANTE, P. Loucos pela vida: a trajetória da reforma psiquiátrica no Brasil. Rio de Janeiro: Fiocruz, 1995.

BAREMBLIT, G. F. Compêndio de análise institucional e outras correntes: teoria e prática. 2. ed. Rio de Janeiro: Rosa dos Tempos, 1994.

BIRMAN, J. Mal-estar na atualidade: a psicanálise e as novas formas de subjetivação. 6. ed. Rio de Janeiro: Civilização Brasileira, 2007.

BRASIL - Ministério da Saúde. Lei n. 8.08o de 19 de setembro de 1990. Dispõe sobre as condições para a promoção, prevenção e recuperação da saúde, a organização e os serviços correspondentes e dá outras providências. Diário Oficial da União, 20 set., 1990 .

BRASIL - Ministério da Saúde. Lei n. 8.142 de 28 de dezembro de 1990. Dispõe sobre a participação da comunidade na gestão do Sistema Único de Saúde - SUS e sobre as transferências intergovernamentais de recursos financeiros na área da saúde e dá outras providências. Diário Oficial da União, 31 dez.199ob.

BRASIL - Ministério da Saúde. Lei n. 10.216, de 6 de abril de 2001.Dispõe sobre a proteção e os direitos das pessoas portadoras de transtornos mentais e redireciona o modelo assistencial em saúde mental. Diário Oficial da União, 9 abril 2001.

BRASIL - Ministério da Saúde. Lei n. 10.708 de 31 de julho de 2003. Institui o auxílio-reabilitação psicossocial para pacientes acometidos de transtornos mentais egressos de internações. Diário Oficial da União, 1 ago. 2003. 
CAMPOS, G. W. S. Saúde pública e saúde coletiva: campo e núcleo de saberes e práticas. Revista Ciência \& Saúde Coletiva, Rio de Janeiro, v. 5, n. 2, p. 219-230, 2000a.

CAMPOS, G. W. S. Um método para análise e cogestão dos coletivos: a constituição do sujeito, a produção de valor de uso e a democracia em instituições: o método da roda. São Paulo: Hucitec, 2ooob.

CARVALHO, S. R. Saúde coletiva e promoção da saúde: sujeito e mudança. São Paulo: Hucitec, 2005 .

COSTA-ROSA, A. O modo psicossocial: um paradigma das práticas substitutivas ao modo asilar. In: AMARANTE, P. Ensaios: subjetividade, saúde mental, sociedade. Rio de Janeiro: Fiocruz, 2000. p. 141-168.

COSTA-ROSA, A. A instituição de saúde mental como dispositivo social de produção de subjetividade. Assis, SP: Unesp, 2006.

COSTA-ROSA, A. et al. Atenção psicossocial rumo a um novo paradigma na saúde mental coletiva. In: AMARANTE, P. (Coord.). Archivos de saúde mental e atenção psicossocial. Rio de Janeiro: Nau, 2003. p. 13-44.

DAHL, Robert A. Sobre a democracia. Tradução de B. Sidou. Brasília: Editora Universidade de Brasília, 2001.

DEVERA, D. A reforma psiquiátrica no interior do Estado de São Paulo: psiquiatria reformada ou mudança paradigmática? 2005. Dissertação (Mestrado em Psicologia) - Faculdade de Ciências e Letras Câmpus de Assis. Universidade Estadual Paulista "Júlio de Mesquita Filho", Assis, SP.

DESVIAT, M. A Reforma psiquiátrica. Rio de Janeiro: Fiocruz, 1999.

FOUCAULT, M. Microfísica do poder. Tradução de R. C. M. Machado. 2 ed. Rio de Janeiro: Graal, 2004.
FOUCAULT, M. A verdade e as formas jurídicas. Tradução de R. C. M. Machado; E. J. Morais. Rio de Janeiro: Nau, 2003.

ILLICH, I. A expropriação da saúde - nêmesis da medicina. Rio de Janeiro: Nova Fronteira, 1975.

LAPASSADE, G. Grupos, Organizações e Instituições. Tradução de H. A. A. Mesquita. 2. ed. Rio de Janeiro: Francisco Alves, 1983.

LIMA, N. T. et al. A saúde na construção do Estado nacional no Brasil: reforma sanitária em perspectiva histórica. In: LIMA, N. T. et al. Saúde e democracia: história e perspectivas do SUS. Rio de Janeiro: Fiocruz: 2005. p. 27-58.

MERHY, E.; AMARAL, H. A reforma psiquiátrica no cotidiano II. São Paulo: Hucitec, 2007.

MONDONI, D.; COSTA-ROSA, A. Reforma psiquiátrica e transição paradigmática no interior do Estado de São Paulo. Psicologia: Teoria e Pesquisa, Brasília, v. 26, n. 1, p. 39-47, jan./mar. 2010.

NUNES, E. D. Saúde coletiva: uma história recente de um passado remoto. In: CAMPOS, G.W.S. [et al.] (Org.). Tratado de saúde coletiva. São Paulo: Hucitec : Rio de Janeiro: Fiocruz, 20o6. p. 295-313.

PAIN, J. S.; ALMEIDA FILHO, N. Saúde coletiva: uma "nova saúde pública" ou campo aberto a novos paradigmas? Revista de Saúde Pública, São Paulo, v. 32, n. 4, 1998, p. 299-316,.

ROSEN, G. Uma história da saúde pública. São Paulo: Hucitec/Unesp, 2006.

ROTELLI, F. et al. Desinstitucionalização. Rio de Janeiro: Hucitec, 1990.

YASUI, S. Rupturas e encontros: desafios da reforma psiquiátrica brasileira. 2006. p. 105-151. Tese (Doutorado em Saúde Pública) - Fundação Oswaldo Cruz, Escola Nacional de Saúde Pública Sérgio Arouca, Rio de Janeiro. 